\title{
A Scheme for Intelligent Design of Large Scale Ship Segment Workshop Based on Fuzzy Evaluation Method
}

\author{
Peng $\mathrm{Xu}^{1, \text { a }}$, Rui $\mathrm{Xue^{2,b }}$ Wei $\mathrm{Fu}^{2, c}$ Weibin Chen ${ }^{1}$ and $\mathrm{Yan}_{\mathrm{Ma}^{2}}$ \\ ${ }^{1}$ NO.716 Research Institute of China Shipbuilding Industry, Lianyungang 222061, \\ China \\ ${ }^{2}$ College of Mechanical and Electrical Engineering, Harbin Engineering University, \\ Harbin 150000, China \\ axupeng716@126.com, b1003542158@qq.com, ' $16788987 @ q q . c o m$
}

\begin{abstract}
The shipbuilding industry, which relates to the national defense construction and the national economy construction, is an important mainstay of our country. In recent two years, Chinese shipbuilding output takes the first place of the world, and China success in becoming the largest shipbuilding country. But our shipbuilding enterprises have great difference with Korea and Japan in production management, such as production planning, duration controlling, etc. Lack of information feedback, the production plan can not intuitively reflect the production schedule changes; the distribution of materials, equipment and workers is difficult to optimize; low management level of production dispatching; poor production efficiency and problems of controlling the construction cycle are seriously hinder Chinese shipbuilders to improve their productivity and management level and become the most powerful shipbuilding country. In this paper, based on intellectualized reconstruction of large ship flat section intelligent workshop, and according to the characteristics of the intelligent workshop, from the workshop layout, logistics facilities, process scheduling, etc are presented.

In this paper, based on the fuzzy evaluation method, three kinds of basic processing and manufacturing forms of the plane section of the large scale ship are analyzed.
\end{abstract}

Keywords: Intelligent Workshop; Fuzzy Evaluation; Particle Swarm Optimization.

\section{Introduction}

With the arrival of marine century, countries have to upgrade the status of marine development and national security in the national strategy, the ocean has become the world competition and the contest venue At present, the domestic shipbuilding factory on the current enterprise human is difficult to meet the future needs of ship manufacturing, especially in the key technology of welding, outfitting and other positions, long period of cultivation technology workers in the field, in the short term can not cultivate competent technical personnel of high technology of ship manufacturing. One of the main ways to solve this problem is to introduce advanced shipbuilding technology and equipment. At present, the ship factories are looking for 
advanced shipbuilding technology and equipment to improve the work efficiency and quality of key positions.

The state has formulated the "made in China 2025" development strategy, which has brought a rare opportunity for the development of shipbuilding enterprises. One of the paths of enterprise transformation and upgrading is the development of advanced shipbuilding technology, the introduction of advanced shipbuilding equipment, the formation of a number of intelligent ship manufacturing workshop, intelligent shipyard, etc.. The large ship plane block intelligent workshop is a new thing, there are no research work in related fields, the production mode should be made by the existing industrial 2 or 3 stage, namely "human judgment analysis + machine manufacturing" to "machine analysis mode + machine manufacturing". In the process of transformation, there are a lot of management and technical work to be determined, such as the evolution of the shop floor, the development of intelligent equipment, business model changes. Accompanied by the transformation of the whole workshop, this paper proposed a ship intelligent manufacturing scheme of digital production line integration technology, the overall layout and process to segment intelligent Workshop on a large ship plane was verified, and the intelligent workshop work efficiency to carry on the analysis, has the vital significance to the transformation of the next step flat section intelligent workshop.

\section{The Overview of the Large Scale Ship Plane Segment Pipeline}

Plane block production line there are two schools in 60s and 70s,the one is Swedish Issa (ESAB), the other is Germany Wentz Ralph (WENZLAFF) and Norway TTS as the representative of the "European style", the two is represented by Japan "japan". With the continuous change of the form of the ship, the ship manufacturing technology is constantly updated, the European style and the Japanese style are also fused with each other, resulting in three kinds of basic processing and manufacturing forms of plane segments. At present, there are three kinds of main workshop layout structure, including the frame method, the vertical loading method and the veneer method, according to the processing sequence and the assembly form.

\subsection{Frame Method}

Frame method is the earliest use of process pipeline, and internal structure, the first welding into a plurality of frames, then the frame has been hanging on plate welding welding and fillet welding in order to improve the efficiency, using gravity welding.

\subsection{Longitudinal Loading}

The longitudinal first method is to use the FCG and FWG automatic welding machine longitudinal angle instead of manual welding processing mode. At present, the design of the large ship is mostly in the form of longitudinal skeleton, so the vertical bone loading method is also a large number of shipyard. The first step method of longitudinal bone can improve the machining efficiency of the plane section, and the deformation of the longitudinal welding process can be reduced obviously by FWG welding. 


\subsection{Veneer Method}

Single plate method is an optimized method for longitudinal bone loading. In the first method of vertical bone in the big board, the first longitudinal welding, and then tailor welded. It is possible to improve the flexibility of the shipyard and the precision of ship manufacture by using single board method. The single board method has higher requirements for the installation and debugging of the equipment, the technical conditions and equipment of the shipyard.

\section{Fuzzy Evaluation Scheme}

Based on the above analysis of the problem of the design of the intelligent workshop of the plane section of the large ship, this paper carries on the project evaluation according to the three principles mentioned in the previous part

\subsection{Determining the Evaluation Factors}

The set of factors that influence the evaluation object is called the factor set. Many factors affect the program, is not the same level, theoretically can enumerate all factors of comprehensive evaluation, but in reality, we only care about the most important and the most basic design factors, in order to reduce the design complexity. According to the first chapter of the production process, determine the evaluation factors set as follows.

$U=\left\{u_{1}, u_{2}, u_{3}, u_{4}\right\}=\{$ Technical performance, maintenance performance, economy, advanced \}

$u_{1}=\left\{u_{11}, u_{12}, u_{13}\right\}=\{$ Unit size, working efficiency, transfer speed of logistics facilities \};

$u_{2}=\left\{u_{21}, u_{22}, u_{23}, u_{24}\right\}=\{$ Environmental requirements, safety, simplicity, easy installation \};

$u_{3}=\left\{u_{31}, u_{32}, u_{33}\right\}=\{$ System cost, system life, installation limits $\}$;

$u_{4}=\left\{u_{41}, u_{42}\right\}=\{$ Degree of modularity $\}$ 。

\subsection{Determining Reserve}

The alternative set is composed of the evaluating results may make to the evaluation object, evaluation level of each factor in U, with "excellent", "good", "medium", "poor" four grades of evaluation:

$V=\left\{v_{1}, v_{2}, v_{3}, v_{4}\right\}=\{$ excellent, good, medium, bad $\}$

\subsection{Determining the Membership of Each Factor}

The membership degree is the degree of membership of each element of the selection. The membership degree of each factor is the degree to which each factor belongs to "excellent", "good", "medium", "general" and "poor". Membership degree can be obtained by statistical method or by membership function. Statistical method is used to determine the degree of membership, please experts to evaluate the factors in $U$. 
The design process is illustrated by the example of the "process efficiency" in the technical performance. As shown in Table 1, "workstation processing efficiency" of the expert evaluation value, similar to this table, the number of factors based on the evaluation of the production of such forms, a total of 12 .

Table 1 Expert Evaluation Value Of "Working Efficiency"

\begin{tabular}{|c|c|c|c|c|}
\hline lan & Expert 1 $\left(\alpha_{m=1}\right)$ & Expert $2\left(\alpha_{m}=1.3\right)$ & Expert $3\left(\alpha_{m}=1.2\right)$ & Expert $4\left(\alpha_{m=1}\right)$ \\
\hline $\begin{array}{l}\text { Frame } \\
\text { method }\end{array}$ & $\begin{array}{llll}0.3, & 0.5, & 0.2, & 0\end{array}$ & 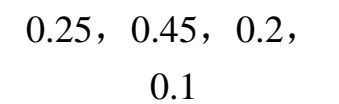 & $0.35,0.5,0.15,0$ & $0.6,0.2,0.2,0$ \\
\hline $\begin{array}{l}\text { Longitu } \\
\text { dinal } \\
\text { loading }\end{array}$ & $\begin{array}{llll}0.6, & 0.2, & 0.2, & 0\end{array}$ & $\begin{array}{llll}0.4, & 0.4, & 0.2, & 0\end{array}$ & $0.45,0.4,0.15,0$ & $0.7,0.2,0.1,0$ \\
\hline $\begin{array}{l}\text { Veneer } \\
\text { method }\end{array}$ & $\begin{array}{llll}0.2, & 0.2, & 0.3, & 0.3\end{array}$ & 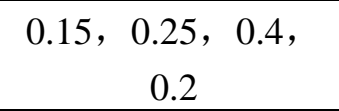 & 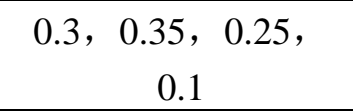 & $\begin{array}{llll}0.1, & 0.3, & 0.5, & 0.1\end{array}$ \\
\hline$\underbrace{u_{11}}_{\text {plan }}$ ex & Expert 5 $\left(\alpha_{m}=2\right)$ & Expert 6 $\left(\alpha_{m}=1.5\right)$ & Expert $7 \quad\left(\alpha_{m}=1.6\right)$ & \\
\hline $\begin{array}{l}\text { Frame } \\
\text { method }\end{array}$ & 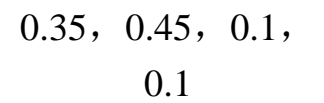 & $\begin{array}{c}0.25,0.3,0.25 \\
0.2\end{array}$ & 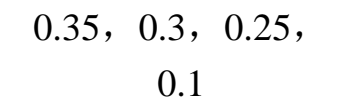 & \\
\hline $\begin{array}{c}\text { Longitu } \\
\text { dinal } \\
\text { loading }\end{array}$ & 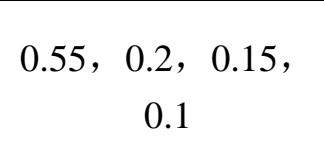 & $\begin{array}{llll}0.4, & 0.3, & 0.2, & 0.1\end{array}$ & $0.55,0.4,0.05,0$ & \\
\hline $\begin{array}{l}\text { Veneer } \\
\text { method }\end{array}$ & $\begin{array}{lll}0.15, & 0.3, & 0.3, \\
& 0.25\end{array}$ & $\begin{array}{llll}0.1, & 0.3, & 0.3, & 0.3\end{array}$ & 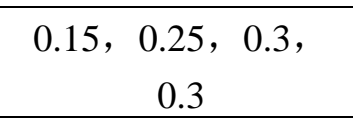 & \\
\hline
\end{tabular}

Here, take the frame method as an example to illustrate the operation process.

The data in the table into the formula (3-13), in the formula, the $\mathrm{K}$ on behalf of the selected concentration of the factors of the serial number, 1 means "good", 2 means "medium":

$$
\begin{array}{lc}
r_{111}=\frac{\sum_{x=1}^{7}\left(\alpha_{m}\right) r_{111 x}}{7}=0.48 ; & r_{112}=\frac{\sum_{x=1}^{7}\left(\alpha_{x}\right) r_{112 x}}{7}=0.53 ; \\
r_{113}=\frac{\sum_{x=1}^{7}\left(\alpha_{x}\right) r_{113 x}}{7}=0.26 ; & r_{114}=\frac{\sum_{x=1}^{7}\left(\alpha_{x}\right) r_{114 x}}{7}=0.10
\end{array}
$$

Normalized processing: :

$r_{11}=\{0.35,0.39,0.19,0.07\}$

\subsection{First Level Fuzzy Evaluation}

According to the previous method, all the two criteria (evaluation factors) are evaluated based on the preference weight coefficient method, and the results are shown in table 2. 
Table 2 Expert Evaluation Value Of Design Scheme Of Large Scale Ship's Intelligent Workshop

\begin{tabular}{|c|c|c|c|c|}
\hline $\begin{array}{l}\text { First-order } \\
\text { criterion }\end{array}$ & $\begin{array}{l}\text { Second-order } \\
\text { criterion }\end{array}$ & Plan 1 & Plan 2 & Plan 3 \\
\hline $\begin{array}{l}\text { Maintenance } \\
\text { performance }\end{array}$ & $\begin{array}{c}\text { environmental } \\
\text { requirements } \\
\text { security } \\
\text { simplicity } \\
4 \text { easy } \\
\text { installation }\end{array}$ & $\begin{array}{cc}(0.36, & 0.32, \\
0.24, & 0.08) \\
(0.32, & 0.24, \\
0.25, & 0.19) \\
(0.15, & 0.22, \\
0.34, & 0.29) \\
(0.24, & 0.27, \\
0.25, & 0.24)\end{array}$ & $\begin{array}{cc}(0.42, & 0.31, \\
0.22, & 0.05) \\
(0.44, & 0.32, \\
0.21, & 0.03) \\
(0.13, & 0.21, \\
0.35, & 0.31) \\
(0.41, & 0.26, \\
0.23, & 0.10)\end{array}$ & $\begin{array}{cc}(0.31, & 0.30, \\
0.20, & 0.19) \\
(0.21, & 0.31, \\
0.36, & 0.12) \\
(0.36, & 0.27, \\
0.22, & 0.15) \\
(0.22, & 0.32, \\
0.34, & 0.12)\end{array}$ \\
\hline $\begin{array}{l}\text { economical } \\
\text { efficiency }\end{array}$ & $\begin{array}{c}\text { device cost } \\
\text { equipment life } \\
\text { process }\end{array}$ & $\begin{array}{cc}(0.31, & 0.26, \\
0.25, & 0.18) \\
(0.21, & 0.24, \\
0.33, & 0.22) \\
(0.26, & 0.31, \\
0.25, & 0.18) \\
\end{array}$ & $\begin{array}{cc}(0.31, & 0.37 \\
0.26, & 0.06) \\
(0.23, & 0.24, \\
0.32, & 0.21) \\
(0.37, & 0.27 \\
0.20, & 0.16) \\
\end{array}$ & $\begin{array}{rc}(0.31, & 0.24, \\
0.23, & 0.22) \\
(0.34, & 0.35, \\
0.23, & 0.08) \\
(0.22, & 0.31, \\
0.27, & 0.20) \\
\end{array}$ \\
\hline Progressiveness & $\begin{array}{c}\text { modularity } \\
\text { standardization } \\
\text { level }\end{array}$ & $\begin{array}{cc}(0.38, & 0.31 \\
0.24, & 0.07) \\
(0.26, & 0.29, \\
0.31, & 0.14) \\
\end{array}$ & $\begin{array}{cc}0.48, & 0.31, \\
0.15, & 0.06) \\
(0.46, & 0.32, \\
0.16, & 0.06) \\
\end{array}$ & $\begin{array}{cc}(0.27, & 0.30, \\
0.31, & 0.13) \\
(0.12, & 0.25, \\
0.37, & 0.26) \\
\end{array}$ \\
\hline
\end{tabular}

Taking the frame method as an example to illustrate the evaluation process.

\subsubsection{Fuzzy Evaluation Matrix}

The first level fuzzy evaluation matrix of the frame method:

Technical:

$$
\underset{\sim}{\sim}=\left[\begin{array}{l}
r_{11} \\
r_{12} \\
r_{12}
\end{array}\right]=\left[\begin{array}{llll}
r_{111} & r_{112} & r_{113} & r_{114} \\
r_{121} & r_{122} & r_{123} & r_{124} \\
r_{131} & r_{132} & r_{133} & r_{134}
\end{array}\right]=\left[\begin{array}{llll}
0.36 & 0.24 & 0.25 & 0.15 \\
0.35 & 0.39 & 0.19 & 0.07 \\
0.17 & 0.25 & 0.32 & 0.26
\end{array}\right] .
$$

Maintainability:

$$
\underset{\sim}{R_{2}}=\left[\begin{array}{l}
r_{21} \\
r_{22} \\
r_{23} \\
r_{24}
\end{array}\right]=\left[\begin{array}{llll}
r_{211} & r_{212} & r_{213} & r_{214} \\
r_{221} & r_{222} & r_{223} & r_{224} \\
r_{231} & r_{232} & r_{233} & r_{234} \\
r_{241} & r_{242} & r_{243} & r_{244}
\end{array}\right]=\left[\begin{array}{llll}
0.36 & 0.32 & 0.24 & 0.08 \\
0.32 & 0.24 & 0.25 & 0.19 \\
0.15 & 0.22 & 0.34 & 0.29 \\
0.24 & 0.27 & 0.25 & 0.24
\end{array}\right]
$$

economical efficiency:

$$
\underset{\sim}{R_{3}}=\left[\begin{array}{c}
r_{31} \\
r_{32} \\
r_{33}
\end{array}\right]=\left[\begin{array}{llll}
r_{311} & r_{312} & r_{313} & r_{314} \\
r_{321} & r_{322} & r_{323} & r_{324} \\
r_{331} & r_{332} & r_{333} & r_{334}
\end{array}\right]=\left[\begin{array}{llll}
0.31 & 0.26 & 0.25 & 0.18 \\
0.21 & 0.24 & 0.33 & 0.22 \\
0.26 & 0.31 & 0.25 & 0.18
\end{array}\right]
$$

Progressiveness: 
$\underset{\sim}{R_{4}}=\left[\begin{array}{l}r_{41} \\ r_{42}\end{array}\right]=\left[\begin{array}{llll}r_{411} & r_{412} & r_{413} & r_{414} \\ r_{421} & r_{422} & r_{423} & r_{424}\end{array}\right]=\left[\begin{array}{cccc}0.38 & 0.31 & 0.24 & 0.07 \\ 0.26 & 0.29 & 0.31 & 0.14\end{array}\right]$

\subsubsection{Determining Weight Set}

In this paper, using the second level fuzzy evaluation, the evaluation factors of the next level have the weighting factors for the higher level factors.

$$
\begin{aligned}
& W=\left(W_{1}, W_{2}, W_{3}, W_{4}\right)=(0.46,0.31,0.13,0.1) \\
& W_{1}=\left(\omega_{11}, \omega_{12}, \omega_{13}\right)=(0.31,0.48,0.21) \\
& W_{2}=\left(\omega_{21}, \omega_{22}, \omega_{23}, \omega_{24}\right)=(0.25,0.4,0.15,0.2) \\
& W_{3}=\left(\omega_{31}, \omega_{32}, \omega_{33}\right)=(0.3,0.45,0.25) \\
& W_{4}=\left(\omega_{41}, \omega_{42}\right)=(0.46,0.54)
\end{aligned}
$$

\subsubsection{First Level Fuzzy Evaluation}

All of the above are substituted into the formula to calculate the first-order fuzzy evaluation of each scheme.

The first level fuzzy evaluation of "frame method":

$$
\begin{aligned}
& \underset{\sim}{B_{1}}=\underset{\sim}{\underset{\sim}{W}} \circ \underset{\sim}{R_{1}}=\left(\omega_{11}, \omega_{12}, \omega_{13}\right) \circ\left[\begin{array}{llll}
r_{111} & r_{112} & r_{113} & r_{114} \\
r_{121} & r_{122} & r_{123} & r_{124} \\
r_{131} & r_{132} & r_{133} & r_{134}
\end{array}\right] \\
& =(0.31,0.48,0.21) \circ\left[\begin{array}{llll}
0.36 & 0.24 & 0.25 & 0.15 \\
0.35 & 0.39 & 0.19 & 0.07 \\
0.17 & 0.25 & 0.32 & 0.26
\end{array}\right] \\
& =(0.32,0.31,0.24,0.14)
\end{aligned}
$$

After treatment

$$
B_{1}=\left(b_{11}, b_{12}, b_{13}, b_{14}\right)=(0.32,0.31,0.24,0.13)
$$

The first level fuzzy evaluation of other factors.

$$
\begin{aligned}
& B_{2}=W_{2} \circ R_{2}=(0.33,0.30,0.29,0.08) \\
& B_{3}=W_{3} \circ R_{3}=(0.25,0.26,0.29,0.20) \\
& B_{4}=W_{4} \circ R_{4}=(0.32,0.30,0.28,0.10)
\end{aligned}
$$

The first level fuzzy evaluation of the method of "longitudinal bone loading":

$$
\begin{aligned}
& B_{\sim}=\underset{\sim}{W_{1}} \circ R_{1}=(0.42,0.33,0.17,0.08) \\
& B_{2}=W_{2} \circ R_{2}=(0.38,0.29,0.24,0.09)
\end{aligned}
$$


$B_{3}=W_{3} \circ R_{3}=(0.29,0.30,0.27,0.14)$

$B_{4}=W_{4} \circ R_{4}=(0.47,0.32,0.15,0.06)$

The first level fuzzy evaluation of the single board method:

$$
\begin{aligned}
& \underset{\sim}{B_{1}}=\underset{\sim}{W_{1}} \circ R_{\sim}=(0.28,0.29,0.26,0.17) \\
& \underset{\sim}{B_{2}}=\underset{\sim}{W_{2}} \circ \underbrace{R_{2}}_{\sim}=(0.26,0.30,0.30,0.14) \\
& \underset{\sim}{B_{3}}=\underset{\sim}{W_{3} \circ \underbrace{}_{\sim}}=(0.30,0.31,0.24,0.15) \\
& B_{4}=W_{4} \circ R_{4}=(0.19,0.27,0.34,0.20)
\end{aligned}
$$

\subsection{Second Level Fuzzy Comprehensive Evaluation}

Frame method :

$\underset{\sim}{B}=\underset{\sim}{W} \circ \underset{\sim}{R}=\left(W_{1}, W_{2}, W_{3}, W_{4}\right) \circ\left[\begin{array}{l}B_{1} \\ B_{2} \\ B_{3} \\ B_{4}\end{array}\right]=(0.46,0.31,0.13,0.1) \circ\left[\begin{array}{cccc}0.32 & 0.31 & 0.24 & 0.13 \\ 0.33 & 0.30 & 0.29 & 0.08 \\ 0.25 & 0.26 & 0.29 & 0.20 \\ 0.32 & 0.30 & 0.28 & 0.10\end{array}\right]$

$=(0.31,0.30,0.27,0.12)$

After treatment:

$B=W \circ R=\left(b_{1}, b_{2}, b_{3}, b_{4}\right)=(0.31,0.30,0.27,0.12)$

The second level fuzzy comprehensive evaluations of other plans

Longitudinal loading :

$B=W \circ R=\left(b_{1}, b_{2}, b_{3}, b_{4}\right)=(0.40,0.31,0.20,0.09)$

Veneer method :

$B=W \circ R=\left(b_{1}, b_{2}, b_{3}, b_{4}\right)=(0.27,0.29,0.28,0.16)$

It can be seen that the "framework" program of "excellent" and "good" evaluation accounted for $61 \%$. The evaluation of "excellent bone" and "good" in the method of "vertical bone loading" accounted for 71\%. The "excellent" and "good" evaluation of the single board method accounted for $56 \%$. The best method is "vertical bone loading method".

\section{Conclusions}

Based on the analysis of the advantages and disadvantages of various weight allocation method in the comprehensive evaluation of the practical problems, demonstration design combined with the large ship plane block intelligent workshop, using the fuzzy evaluation method based on improved weight vector. Based on the above research, the design scheme of two level fuzzy evaluation section intelligent Workshop on large ship plane were evaluated. The evaluation by using the method of 
weight coefficient based on the preference, the results of the method with step evaluation is more prominent, more can reflect the experts' preference potential, has certain guidance meaning.

\section{Acknowledgments}

This work was financially supported by Digital workshop terminology and general technical requirements for standard research and test verification [2015]415 which is the part of the project: Intelligent manufacturing special in 2015.

\section{References}

[1] Li Qin, Liu Ying. The door of ship intelligent era in China 2015-12-02004.

[2] shipbuilding industry "12th Five-Year" development plan. China Ship news, 2012-01-06003.

[3] "development plan of shipbuilding industry in 12th Five-Year". Mechanical research and application, 2012, 02:145

[4] shipbuilding industry "12th Five-Year" development plan. Ship Standardization Engineer, 2012, 03:16-23

[5] Yang Hongying. Development and application of dual power digital shipbuilding can be expected

[6] Wu Chen. Chinese shipbuilding industry is expected to close to the level of Japan and South Korea within 5 years

[7] Wu Chen. To speed up the embrace of Intelligent Manufacturing China shipbuilding industry is expected to close to the level of Japan and South Korea within 5 years

[8] Shen Lan. Study on the core competitiveness of shipbuilding enterprises in China. Shanghai Academy of Social Sciences, 2006 